\title{
Influence of curcumin on the pharmacodynamics and pharmacokinetics of gliclazide in animal models
}

\author{
Leela Krishna Vatsavai' \\ Eswar Kumar Kilari² \\ 'Department of Pharmaceutical \\ Sciences, Jawaharlal Nehru \\ Technological University, Hyderabad, \\ Telangana, ${ }^{2}$ Pharmacology Division, AU \\ College of Pharmaceutical Sciences, \\ Andhra University, Visakhapatnam, \\ Andhra Pradesh, India
}

This article was published in the following Dove Press journal:

Journal of Experimental Pharmacology

17 November 2016

Number of times this article has been viewed

Purpose: Patients suffering from obesity-related diseases use multiple prescription drugs to control their condition, and it is therefore essential to determine the safety and efficacy of any combination. Gliclazide is one of the most commonly used drug of choice for treatment of type 2 diabetes, and curcumin is a widely used herbal supplement to counter obesity condition. The objective of this study was to investigate the effect of oral administration of curcumin on pharmacodynamics and pharmacokinetics of gliclazide in rats and rabbits to further evaluate the safety and effectiveness of this combination.

Methods: Influence of curcumin on the activity of gliclazide was determined by conducting single- and multiple-dose interaction studies in rats (normal and diabetic) and rabbits. Blood samples collected at predetermined time intervals from experimental animals were used for the estimation of glucose and insulin levels by using automated clinical chemistry analyzer and radioimmunoassay method, respectively. The insulin resistance and $\beta$-cell function were determined by homeostasis model assessment. Additionally, serum gliclazide levels in rabbits were analyzed by high-performance liquid chromatography.

Results: Gliclazide showed peak reduction in blood glucose levels at 2 and 8 hours in rats and at 3 hours in rabbits. This activity of gliclazide was not altered by single-dose treatment with curcumin. However, in multiple-dose interaction studies, samples analyzed from all time points showed subtle but significantly greater reduction in percent blood glucose ranging from $23.38 \%$ to $42.36 \%$ in normal rats, $27.63 \%$ to $42.27 \%$ in diabetic rats, and $16.50 \%$ to $37.88 \%$ in rabbits. The pharmacokinetics of gliclazide was not altered by single- or multiple-dose curcumin treatments in rabbits.

Conclusion: The interaction of curcumin with gliclazide up on multiple-dose treatment was pharmacodynamic in nature, indicating the need for periodic monitoring of glucose levels and dose adjustment as necessary when this combination is prescribed to obese patients.

Keywords: curcumin, gliclazide, herb-drug interaction, pharmacokinetics, homeostasis model assessment, diabetes

\section{Introduction}

Polypharmacy is the concurrent use of multiple medications. It can be associated with the prescription and/or use of unnecessary medications at dosages or frequencies higher than therapeutically essential. Polypharmacy is a common practice to treat single disorder or multiple disorders which occur simultaneously. In developing countries, where no strict control on over-the-counter drug distribution exists and lack of medical awareness in the consumer sector, polypharmacy is found to be more prevalent. Herbal medicines/supplements are widely used today either solely or in combination with modern pharmaceuticals. These therapeutic combinations may be toxic at the 
doses taken adding a new layer of complexity to patient care and thereby pose a significant public health problem. The possible adverse effects of herb-drug interactions remain to be explained and poorly understood. Significant changes in the pharmacological or toxicological effects of either component may be seen when herbal active constituents and drugs are given in combination and therefore, it is important to study herb-drug interactions. ${ }^{1}$ Obesity is recognized as a worldwide crisis and represents an area of increasing concern because of its predominant effects on mortality and economics. Clinical pathophysiological studies indicate that obesity leads to risk factors like diabetes, insulin resistance, hypertension, dyslipidemia, and heart failure. ${ }^{2}$ Management of such conditions and complications requires prolonged treatment with combinations of drugs and/ or herbal active constituents. Patients with obesity are prone to develop diabetes, and maintenance of normal blood glucose level in these individuals is very critical for the prevention of undesirable complications associated with both hyperglycemia and hypoglycemia. Oral hypoglycemic agents are used in the treatment of type 2 diabetes, of which gliclazide (secondgeneration sulfonylurea derivative) is the preferred choice of drug. It acts by selectively inhibiting pancreatic $\mathrm{K}^{+}$adenosine triphosphatase channels. ${ }^{3}$ Further, gliclazide is reported to have antioxidant properties, reduced propensity to induce severe hypoglycemia, and other hemobiological effects. ${ }^{4}$ Gliclazide is primarily metabolized by hepatic microsomal enzymes CYP2C9 and partly by CYP3A4. ${ }^{3}$

Curcumin is the active ingredient present in medicinal plant Curcuma longa, also known as turmeric. From decades, it has been widely used in Ayurveda, Unani, and Siddha medicine to cure various diseases. Curcuminoids often referred to simply as curcumin typically contains three major curcuminoids: curcumin, demethoxycurcumin, and bis-demethoxycurcumin. ${ }^{5}$ Curcumin is reported to be used for a wide variety of diseases and conditions including those of the skin, pulmonary, gastrointestinal system, ache, pain, liver, and disease manifestations such as obesity, type-2 diabetes, ${ }^{6}$ etc. Curcumin is readily available in market in various dose formulations and is consumed by people as herbal medicine/ supplement/spice because of its known medicinal properties. It is reported that curcumin's beneficial effects on obesity is due to its anti-inflammatory properties by inhibiting production of pro-inflammatory cytokines such as TNF- $\alpha$, MCP-1, and nitric oxide from adipocytes. ${ }^{7}$ It is proven in vivo that curcumin has the potential to lower serum and hepatic triglycerides, ${ }^{8}$ free fatty acids, total cholesterol, low-density lipoprotein, leptin, ${ }^{9}$ and also inhibits adipogenesis and angiogenesis in adipocytes. ${ }^{10}$ Research suggest that patients pretreated with curcumin are less likely to develop symptoms of and complications associated with obesity. ${ }^{11}$ Oral administration of curcumin to animal models significantly displayed antihyperglycemic activity, hypolipidemic activity, ${ }^{12}$ and decreased body weight, suggesting beneficial effects in treatment of diabetes and obesity. Curcumin metabolism and its interactions with drugs has been studied, and it is observed in vitro that curcumin-mediated chemo-protection was achieved by inhibition of drug-metabolizing enzymes such as CYP1A1, $1 \mathrm{~A} 2$, and $2 \mathrm{~B} 1 .{ }^{13}$ It is pointed out that curcumin exhibits noncompetitive inhibition of CYP2C9 and CYP2C11 in liver microsomes and also modulates CYP1A catalytic activity. ${ }^{14}$ Although in vitro investigations on curcumin suggests that it might be an inhibitor of particular CYP enzyme, correlation of the same to its in vivo effects is hypothetical and opens an avenue for further investigation. To date, only little in vivo work is done to relate the interaction of curcumin on CYP enzymes. Based on the background information, the present study was designed and undertaken with the hypothesis that pretreatment of curcumin will influence the pharmacodynamics and pharmacokinetics of gliclazide in animal models.

\section{Materials and methods Drugs and chemicals}

Gliclazide was obtained as a gift sample from Dr Reddy's Laboratories (Bachupally, Hyderabad, Telangana, India). Curcumin commercially available as pure powder capsule (95\%) was obtained from Quality Supplements and Vitamins (Fort Lauderdale, FL, USA). Alloxan monohydrate was purchased from Loba Chemie (Mumbai, Maharashtra, India). All reagents and chemicals used in the study were of analytical grade.

\section{Animals}

Eight to 9-week-old male albino rats weighing between 170 and $250 \mathrm{~g}$ were procured from Vivo Biotech (Hyderabad, Telangana, India), and 3-month-old male albino rabbits weighing between 1 and $1.5 \mathrm{~kg}$ were procured from Rabiroof (Hyderabad, Telangana, India). They were maintained under standard laboratory husbandry conditions at $25^{\circ} \mathrm{C} \pm 2^{\circ} \mathrm{C}$ and $50 \% \pm 15 \%$ relative humidity with a 12 -hour light/dark cycle. Animals were fed with a commercially available pellet diet (Rayan's Boitechnologies Pvt Ltd, Hyderabad, Telangana, India) and water was provided ad libitum. Animals were fasted for 10 hours prior to the experiment, and during the experiment they were withdrawn from feed. The animal experiments were performed after prior approval of study 
protocol by the Institutional Animal Ethics Committee (Reg No DLL/IAEC/2013/02/04). The study was also conducted in accordance with the guidelines provided by the Committee for the Purpose of Control and Supervision of Experiments on Animals.

\section{Study design}

Curcumin doses of 200 and $100 \mathrm{mg} / \mathrm{kg}$ were calculated from human oral therapeutic dose based on body surface area for rats and rabbits, respectively. ${ }^{15}$ From the results of gliclazide dose-effect relationship study conducted in normal rats and rabbits, the doses of 2 and $4 \mathrm{mg} / \mathrm{kg}$ body weight were selected, respectively, for administration in animals. ${ }^{16}$ Oral dose formulation for curcumin was prepared by suspending in $0.5 \%$ carboxymethyl cellulose $\mathrm{Na}$. Gliclazide solution was prepared by dissolving in few drops of $0.1 \mathrm{~N} \mathrm{NaOH}$ and the final volume was made with water. ${ }^{17}$ The design of the study is as follows:

Stage 1: Pharmacodynamic interaction in normal rats. ${ }^{3}$

Stage 2: Pharmacodynamic interaction in diabetic rats. ${ }^{3}$

Stage 3: Pharmacodynamic and pharmacokinetic interaction in normal rabbits. ${ }^{18}$

\section{Pharmacodynamic interaction in normal rats}

Six rats were selected for stage 1 experiment. These rats were given gliclazide via the oral route at $2 \mathrm{mg} / \mathrm{kg}$ body weight, and their blood samples were collected at predetermined time points. With a week washout period between each experiment, similar procedure was performed with either orally administered curcumin only or combination treatment with both curcumin and gliclazide at the previously mentioned doses. After these single-dose interaction studies, the same group of animals were given daily treatments with curcumin for the next 20 days with regular feeding. On day 21 , animals were fasted for 10 hours before administering curcumin. After 30 minutes, the animals were given gliclazide at $2 \mathrm{mg} / \mathrm{kg}$ body weight. Blood samples were collected at predetermined time intervals after each treatment with gliclazide alone, curcumin alone, or combination treatments (single and multiple).

\section{Pharmacodynamic interaction in diabetic rats}

For stage 2 experiments, diabetes was induced in rats as previously described. ${ }^{19}$ Briefly, diabetes was induced in rats by the administration of alloxan monohydrate in two divided doses, that is, 100 and $50 \mathrm{mg} / \mathrm{kg}$ body weight intraperitoneally on 2 consecutive days. After 72 hours, blood samples were collected from surviving rats by retro-orbital puncture, and blood glucose levels were measured using automated clinical chemistry analyzer. Six rats with blood glucose levels $\geq 200$ $\mathrm{mg} / \mathrm{dL}$ were considered as diabetic and selected for the study. The same treatment protocols as described in stage 1 were tested in the diabetic rats.

\section{Pharmacodynamic and pharmacokinetic interaction in normal rabbits}

Six rabbits were selected for stage 3 experiment. These rabbits were given gliclazide via the oral route at $4 \mathrm{mg} / \mathrm{kg}$ body weight, and their blood was collected at predetermined time points. With a week washout period between experiments, similar procedure was performed with either orally administered curcumin or combination treatment with both curcumin and gliclazide at the previously mentioned doses. After this single-dose interaction study, the same animals received daily treatments with curcumin for the next 20 days with regular feeding. On day 21, the animals were fasted for 10 hours before administering curcumin. After 30 minutes, the animals received gliclazide at $4 \mathrm{mg} / \mathrm{kg}$ body weight. Blood samples were collected at predetermined time intervals after each treatment of gliclazide, curcumin, or combination treatments (single and multiple).

\section{Collection of blood samples}

Blood samples were collected from retro-orbital plexus ${ }^{20}$ of each rat at $0,1,2,3,4,6,8$, and 12 hours. Blood samples were withdrawn from the marginal ear vein of each rabbit at $0,1,2,3,4,6,8,10,12,16$, and 24 hours. The blood samples collected at all the intervals (except for 16 and 24 hours in rabbits) were tested for blood glucose by using automated clinical chemistry analyzer. Blood samples collected at 2- and 8-hour time intervals in normal, diabetic rats and at 3 hours from rabbits were also used for the estimation of serum insulin by radioimmunoassay method. ${ }^{17}$ These intervals were selected based on the peak percent blood glucose levels observed in rats and rabbits. ${ }^{17}$ Additionally, blood samples collected from rabbits were used for the estimation of gliclazide concentration in serum by high-performance liquid chromatography method.

\section{Determination of insulin resistance index and $\beta$-cell function}

The insulin resistance index and $\beta$-cell function were assessed by the Homeostatic Model Assessment protocol and was calculated as follows: 17,21,22 
Insulin resistance $=(\mathrm{FSI} \times \mathrm{FSG}) / 22.5$ and

$\beta$-cell function $=(20 \times \mathrm{FSI}) /(\mathrm{FSG}-3.5) \times 100$

where fasting serum insulin (FSI) is expressed in $\mu \mathrm{IU} / \mathrm{mL}$ and fasting serum glucose (FSG) in $\mathrm{mg} / \mathrm{dL}$.

\section{Pharmacokinetic analysis}

Pharmacokinetic parameters of gliclazide in rabbit serum such as peak serum concentration $\left(\mathrm{C}_{\max }\right)$, peak time $\left(\mathrm{T}_{\max }\right)$, area under the concentration time curve, area under first moment curve, terminal half-life, elimination rate constant, mean resident time, and clearance were estimated by using Kinetica 5.0 software.

\section{Data and statistical analysis}

Data are expressed as mean \pm standard deviation values. Student's paired $t$-test was used as statistical tool and $p<0.05$ is considered as statistically significant.

\section{Results}

\section{Pharmacodynamic interaction between curcumin and gliclazide}

Gliclazide produced hypoglycemic activity in normal rats with maximum biphasic reduction of $41.66 \% \pm 1.70 \%$ and $39.49 \% \pm 1.82 \%$ (Table 1 ) and antihyperglycemic activity in diabetic rats with peak biphasic reduction of $43.17 \% \pm 0.90 \%$ and $40.91 \% \pm 1.56 \%$ at 2 - and 8 -hour time intervals, respectively (Table 2). Peak hypoglycemic activity was observed with maximum reduction of $34.10 \% \pm 1.90 \%$ at 3 -hour time interval in rabbits (Table 3 ). Curcumin alone did not produce any significant change in the blood glucose level of both rats (normal and diabetic) and rabbits. Single-dose combination of curcumin with gliclazide did not induce any significant

Table I Mean percent blood glucose reduction of gliclazide in presence and absence of curcumin in normal rats $(n=6)$

\begin{tabular}{lllll}
\hline Time (h) & Gliclazide & Curcumin & $\begin{array}{l}\text { Gliclazide } \\
\text { +curcumin } \\
\text { (SDT) }\end{array}$ & $\begin{array}{l}\text { Gliclazide } \\
+ \text { curcumin } \\
\text { (MDT) }\end{array}$ \\
\hline 1 & $31.51 \pm 1.69$ & $-8.63 \pm 1.93$ & $31.08 \pm 1.5 I$ & $32.34 \pm 2.31$ \\
2 & $41.66 \pm 1.70$ & $-3.34 \pm 1.24$ & $40.41 \pm 1.49$ & $42.36 \pm 2.20$ \\
3 & $28.98 \pm 2.04$ & $1.40 \pm 1.29$ & $29.01 \pm 4.44$ & $35.44 \pm 2.96 *$ \\
4 & $23.46 \pm 2.65$ & $3.32 \pm 2.40$ & $23.60 \pm 1.35$ & $33.75 \pm 1.73^{*}$ \\
6 & $30.22 \pm 2.19$ & $5.45 \pm 1.81$ & $30.19 \pm 4.33$ & $36.69 \pm 1.25^{*}$ \\
8 & $39.49 \pm 1.82$ & $4.73 \pm 2.34$ & $39.24 \pm 1.37$ & $42.04 \pm 2.42^{*}$ \\
10 & $24.24 \pm 2.40$ & $3.15 \pm 2.79$ & $25.97 \pm 3.65$ & $33.39 \pm 2.22^{*}$ \\
12 & $18.83 \pm 2.17$ & $6.16 \pm 2.33$ & $17.15 \pm 2.17$ & $23.38 \pm 2.16^{*}$ \\
\hline
\end{tabular}

Notes: Data expressed as mean \pm standard deviation. *Statistically significant when compared with gliclazide control.

Abbreviations: MDT, multiple-dose treatment; SDT, single-dose treatment.
Table 2 Mean percent blood glucose reduction of gliclazide in presence and absence of curcumin in diabetic rats $(n=6)$

\begin{tabular}{lllll}
\hline Time (h) & Gliclazide & Curcumin & $\begin{array}{l}\text { Gliclazide } \\
\text { curcumin } \\
\text { (SDT) }\end{array}$ & $\begin{array}{l}\text { Gliclazide } \\
\text { curcumin } \\
\text { (MDT) }\end{array}$ \\
\hline 1 & $30.84 \pm 2.08$ & $1.08 \pm 0.60$ & $31.98 \pm 1.21$ & $30.33 \pm 1.45$ \\
2 & $43.17 \pm 0.90$ & $1.46 \pm 1.63$ & $43.54 \pm 0.84$ & $42.27 \pm 2.07$ \\
3 & $31.90 \pm 1.86$ & $0.61 \pm 2.05$ & $32.35 \pm 1.55$ & $36.07 \pm 2.06 *$ \\
4 & $26.53 \pm 2.25$ & $2.46 \pm 2.56$ & $26.47 \pm 1.81$ & $37.62 \pm 1.65^{*}$ \\
6 & $35.53 \pm 2.74$ & $5.15 \pm 1.99$ & $34.02 \pm 1.76$ & $39.17 \pm 1.80^{*}$ \\
8 & $40.91 \pm 1.56$ & $6.04 \pm 1.90$ & $42.12 \pm 1.55$ & $41.56 \pm 1.50$ \\
10 & $27.95 \pm 1.32$ & $4.14 \pm 0.97$ & $27.44 \pm 1.43$ & $32.64 \pm 2.30^{*}$ \\
12 & $24.50 \pm 1.00$ & $3.55 \pm 2.19$ & $23.47 \pm 3.91$ & $27.63 \pm 1.00^{*}$ \\
\hline
\end{tabular}

Notes: Data expressed as mean \pm standard deviation. *Statistically significant when compared with gliclazide control.

Abbreviations: MDT, multiple-dose treatment; SDT, single-dose treatment.

Table 3 Mean percent blood glucose reduction of gliclazide in presence and absence of curcumin in rabbits $(n=6)$

\begin{tabular}{lllll}
\hline Time (h) & Gliclazide & Curcumin & $\begin{array}{l}\text { Gliclazide } \\
\text { +curcumin } \\
\text { (SDT) }\end{array}$ & $\begin{array}{l}\text { Gliclazide } \\
\text { +curcumin } \\
\text { (MDT) }\end{array}$ \\
\hline 1 & $18.75 \pm 2.02$ & -0.52 .46 & $18.11 \pm 1.41$ & $19.11 \pm 1.96$ \\
2 & $29.39 \pm 3.74$ & $1.59 \pm 1.13$ & $29.09 \pm 0.88$ & $29.46 \pm 2.84$ \\
3 & $34.10 \pm 1.90$ & $-0.36 \pm 1.08$ & $34.48 \pm 1.17$ & $37.88 \pm 1.30^{*}$ \\
4 & $26.15 \pm 1.94$ & $3.48 \pm 2.80$ & $26.47 \pm 0.82$ & $29.12 \pm 2.15^{*}$ \\
6 & $23.10 \pm 2.98$ & $4.20 \pm 1.28$ & $23.32 \pm 1.29$ & $26.51 \pm 3.14^{*}$ \\
8 & $17.16 \pm 1.36$ & $9.63 \pm 3.67$ & $17.75 \pm 1.43$ & $23.31 \pm 2.13^{*}$ \\
10 & $15.00 \pm 3.12$ & $5.26 \pm 1.61$ & $15.66 \pm 1.34$ & $19.13 \pm 1.96^{*}$ \\
12 & $10.65 \pm 1.03$ & $10.68 \pm 2.22$ & $10.45 \pm 0.79$ & $16.50 \pm 1.5 I^{*}$ \\
\hline
\end{tabular}

Notes: Data expressed as mean \pm standard deviation. *Statistically significant when compared with gliclazide control.

Abbreviations: MDT, multiple-dose treatment; SDT, single-dose treatment.

changes in percent blood glucose reduction, insulin levels, insulin resistance, and $\beta$-cell function in animal models. However, multiple-dose combination of curcumin with gliclazide produced significantly greater reduction in percent blood glucose reduction at 3-, 4-, 6-, 8-, 10-, and 12-hour intervals after treatment in normal rats and rabbits when compared with gliclazide control. Similarly, greater significant increase in percent blood glucose reduction was observed in diabetic rats except at 8-hour interval. No significant changes were observed in insulin levels, insulin resistance, and $\beta$-cell function (Tables 4-6) in both the animal models.

\section{Pharmacokinetic interaction between curcumin and gliclazide}

The mean concentration versus time curve after oral administration of gliclazide in presence of curcumin is shown in Figure 1. The pharmacokinetic parameters of gliclazide 
Table 4 Effect of curcumin on glucose insulin homeostasis of gliclazide in normal rats $(n=6)$

\begin{tabular}{|c|c|c|c|c|c|c|}
\hline \multirow[t]{2}{*}{ Parameter } & \multicolumn{2}{|c|}{ Insulin $(\mu \mathrm{IU} / \mathrm{mL})$} & \multicolumn{2}{|c|}{ Insulin resistance ${ }^{a}$} & \multicolumn{2}{|c|}{$\beta$-cell function ${ }^{a}$} \\
\hline & $2 \mathrm{~h}$ & $8 \mathrm{~h}$ & $2 \mathrm{~h}$ & $8 \mathrm{~h}$ & $2 \mathrm{~h}$ & $8 \mathrm{~h}$ \\
\hline Gliclazide & $12.2 \mid \pm 0.45$ & $11.76 \pm 0.20$ & $29.70 \pm 2.40$ & $29.61 \pm 1.08$ & $477.8 I \pm I 5.6 I$ & $442.79 \pm 17.85$ \\
\hline Curcumin & $7.85 \pm 0.76$ & $7.65 \pm 0.42$ & $34.13 \pm 3.26$ & $30.63 \pm 1.71$ & $166.50 \pm 16.67$ & $176.47 \pm 10.38$ \\
\hline Gliclazide + curcumin (SDT) & $12.33 \pm 0.67$ & $11.80 \pm 0.20$ & $32.06 \pm 2.03$ & $31.28 \pm 0.95$ & $448.76 \pm 27.67$ & $421.00 \pm 23.44$ \\
\hline Gliclazide + curcumin (MDT) & $\mid 2.09 \pm 0.21$ & $11.54 \pm 0.52$ & $29.82 \pm 1.06$ & $28.64 \pm 2.09$ & $465.16 \pm 14.11$ & $441.40 \pm 24.00$ \\
\hline
\end{tabular}

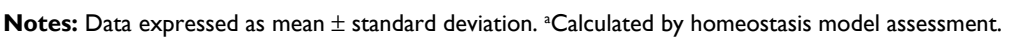

Abbreviations: MDT, multiple-dose treatment; SDT, single-dose treatment.

Table 5 Effect of curcumin on glucose insulin homeostasis of gliclazide in diabetic rats $(n=6)$

\begin{tabular}{|c|c|c|c|c|c|c|}
\hline \multirow[t]{2}{*}{ Parameter } & \multicolumn{2}{|c|}{ Insulin $(\mu \mathrm{IU} / \mathrm{mL})$} & \multicolumn{2}{|c|}{ Insulin resistance $^{a}$} & \multicolumn{2}{|c|}{$\beta$-cell function ${ }^{a}$} \\
\hline & $2 \mathrm{~h}$ & $8 \mathrm{~h}$ & $2 \mathrm{~h}$ & $8 \mathrm{~h}$ & $2 \mathrm{~h}$ & $8 \mathrm{~h}$ \\
\hline Gliclazide & $14.13 \pm 0.32$ & $12.58 \pm 0.75$ & $89.78 \pm 1.67$ & $83.14 \pm 5.74$ & $202.68 \pm 7.61$ & $173.29 \pm 9.67$ \\
\hline Curcumin & $7.21 \pm 0.29$ & $6.86 \pm 0.31$ & $82.4 I \pm 4.84$ & $76.87 \pm 3.33$ & $56.82 \pm 1.76$ & $55.19 \pm 2.76$ \\
\hline Gliclazide + curcumin (SDT) & $|4.3| \pm 0.5 \mid$ & $|2.32 \pm 0.7|$ & $97.43 \pm 3.81$ & $85.98 \pm 5.15$ & $191.26 \pm 6.73$ & $160.64 \pm 10.14$ \\
\hline Gliclazide + Ccrcumin (MDT) & $14.26 \pm 0.42$ & $|3.4| \pm 0.49$ & $94.44 \pm 4.76$ & $90.05 \pm 3.32$ & $195.99 \pm 4.92$ & $181.66 \pm 8.46$ \\
\hline
\end{tabular}

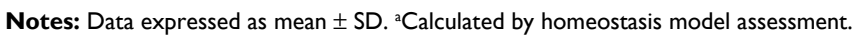

Abbreviations: MDT, multiple-dose treatment; SD, standard deviation; SDT, single-dose treatment.

Table 6 Effect of curcumin on glucose insulin homeostasis of gliclazide in rabbits $(\mathrm{n}=6)$

\begin{tabular}{llll}
\hline Parameter & $\begin{array}{l}\text { Insulin } \\
(\boldsymbol{\mu l U} / \mathbf{m L})\end{array}$ & Insulin resistance & \\
\cline { 2 - 4 } & $\mathbf{3 ~ h}$ & $\mathbf{3} \mathbf{~ h}$ & $\mathbf{3}$-cell function \\
\hline Gliclazide & $20.77 \pm 0.76$ & $56.14 \pm 2.53$ & $724.74 \pm 31.96$ \\
Curcumin & $8.94 \pm 0.30$ & $37.87 \pm 1.67$ & $194.60 \pm 5.63$ \\
Gliclazide + & $22.39 \pm 1.19$ & $63.38 \pm 4.06$ & $756.90 \pm 37.40$ \\
$\begin{array}{l}\text { curcumin (SDT) } \\
\text { Gliclazide + }\end{array}$ & $20.73 \pm 0.87$ & $54.36 \pm 2.55$ & $747.06 \pm 31.83$ \\
curcumin (MDT) & & & \\
\hline
\end{tabular}

Notes: Data expressed as mean \pm standard deviation. ${ }^{2}$ Calculated by homeostasis model assessment.

Abbreviations: MDT, multiple-dose treatment; SD, standard deviation; SDT, single-dose treatment.

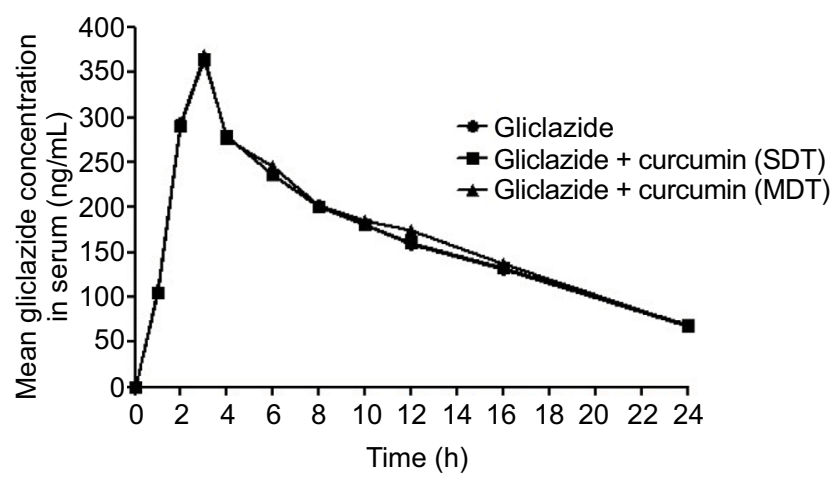

Figure I Mean gliclazide concentration in serum $(\mathrm{ng} / \mathrm{mL})$ before and after treatment with curcumin in rabbits $(n=6)$.

Abbreviations: MDT, multiple-dose treatment; SDT, single-dose treatment. alone and in the presence of curcumin following single- and multiple-dose administrations are given in Table 7. Curcumin in presence of gliclazide, both in single- and multiple-dose combinations, did not alter the pharmacokinetics of gliclazide in rabbits.

\section{Discussion}

Drug interactions studies are an important aspect of pharmacology research, and such interactions are usually evaluated in animal models. ${ }^{23}$ Although animal models can never replace the need for comprehensive studies in human subjects, their use can provide important information for understanding the mechanisms of drug interactions. The present study is designed to evaluate the influence of curcumin on the activity of gliclazide in animal models. Normal rats were used to identify the interaction and diabetic rats aided to validate the interaction in the actually used condition of the drug. Rabbit model was used further to validate the same in a dissimilar species. ${ }^{18}$ Consistent with previous reports showing that rats are more sensitive to gliclazide treatment, ${ }^{3}$ gliclazide produced a biphasic response at 2 - and 8 -hour intervals in rat model when administered alone, which might be due to biliary excretion and enterohepatic recycling. ${ }^{3,24,25}$ The biphasic effect was not seen in rabbit model and the maximum reduction in percent blood glucose was observed at 3-hour interval. This might due to the absence of enterohepatic recycling in rabbits. According to a recent clinical study, enterohepatic 
Table 7 Mean pharmacokinetic parameters of gliclazide before and after administration of curcumin in rabbits $(n=6)$

\begin{tabular}{llll}
\hline Pharmacokinetic parameter & Gliclazide & Gliclazide + curcumin (SDT) & Gliclazide + curcumin (MDT) \\
\hline $\mathrm{C}_{\text {max }}(\mathrm{ng} / \mathrm{mL})$ & $363.01 \pm 6.09$ & $364.19 \pm 8.63$ & $369.46 \pm 4.36$ \\
$\mathrm{~T}_{\text {max }}(\mathrm{h})$ & $3.00 \pm 0.00$ & $3.00 \pm 0.00$ & $3.00 \pm 0.00$ \\
$\mathrm{AUC}_{\text {last }}(\mathrm{h} \mathrm{ng} / \mathrm{mL})$ & $3,959 \pm 14.66$ & $3,967.76 \pm 48.07$ & $4,062.62 \pm 26.14$ \\
$\mathrm{AUC}_{\text {inf }}(\mathrm{h} \mathrm{ng} / \mathrm{mL})$ & $4,954.1 \mathrm{I} \pm 38.14$ & $5,008.30 \pm 102.22$ & $4,963.64 \pm 88.77$ \\
$\mathrm{AUMC}_{\text {last }}(\mathrm{h} \mathrm{ng} / \mathrm{mL})$ & $37,998.28 \pm 144.77$ & $38,278.83 \pm 628.45$ & $39,218.32 \pm 292.54$ \\
$\mathrm{AUMC}_{\text {inf }}(\mathrm{h} \mathrm{ng} / \mathrm{mL})$ & $76,368.86 \pm 1,676.56$ & $78,861.19 \pm 3,792.62$ & $72,887.66 \pm 4,837.15$ \\
$\mathrm{~T}_{1 / 2}(\mathrm{~h})$ & $10.11 \pm 0.16$ & $10.38 \pm 0.31$ & $9.19 \pm 0.87$ \\
$\mathrm{~K}_{\text {el }}(\mathrm{I} / \mathrm{h})$ & $0.07 \pm 0.00$ & $0.07 \pm 0.00$ & $0.08 \pm 0.01$ \\
$M R T(\mathrm{~h})$ & $9.60 \pm 0.01$ & $9.65 \pm 0.06$ & $9.65 \pm 0.02$ \\
$\mathrm{CL}(\mathrm{L} / \mathrm{h})$ & $0.07 \pm 0.00$ & $0.07 \pm 0.00$ & $0.08 \pm 0.01$ \\
\hline
\end{tabular}

Note: Data expressed as mean \pm standard deviation.

Abbreviations: AUC, area under the concentration time curve; $\mathrm{AUMC}$, area under first moment curve; $\mathrm{CL}$, clearance; $\mathrm{C}_{\max }$, peak serum concentration; $\mathrm{K}_{\mathrm{e}}$; elimination rate constant; MDT, multiple-dose treatment; MRT, mean residence time; SD, standard deviation; SDT, single-dose treatment; $T_{\max }, P$ peak time; $T_{1 / 2}$, terminal half-life.

recirculation is also observed in humans and is therefore consistent with our data from the animal experiments substantiating the correlation between our preclinical data to human. ${ }^{26}$ Gliclazide is known for its hypoglycemic activity in rat mediated by blocking $\mathrm{K}^{+}$channels in the pancreatic $\beta$-cells, thereby stimulating insulin secretion and antihyperglycemic activity in diabetic rats by increasing tissue uptake of glucose, respectively. ${ }^{27,28}$ Insulin levels were estimated at time intervals, where greater reduction in percent blood glucose levels were observed both in rats (2- and 8-hour intervals) and in rabbits (3-hour interval). ${ }^{17}$

Any drug/herbal active constituent, which is a potential inducer or inhibitor of drug-metabolizing enzymes, may alter the pharmacokinetics and pharmacodynamics activity of the substrate. Curcumin has the potential to cause herb-drug interaction when administered with other drugs. ${ }^{29}$ This study revealed the influence of curcumin on the pharmacodynamic activity of gliclazide alone and in combination using singleand multiple-dose treatments in rats and rabbits. The end points were evaluated in terms of glucose level (\% reduction), insulin level, $\beta$-cell function, and insulin resistance using Homeostatic Model Assessment and pharmacokinetics of gliclazide in rabbits. In the present study, no significant changes were observed in pharmacodynamics and pharmacokinetics of gliclazide following single-dose administration with curcumin. Multiple-dose treatment of curcumin resulted in minor change to significant increase in percent blood glucose reduction in rats (normal and diabetic) and rabbits when compared with gliclazide control. The resulted changes in glucose levels might be due to additive effect of curcumin in presence of gliclazide. This effect of curcumin can be attributed due to one or more possible mechanisms as reported earlier. Curcumin is reported to exhibit hypoglycemic activity in rat by regulation of polyol pathway ${ }^{30}$ or by suppression of oxidative stress and inflammatory cytokines. ${ }^{31}$ Previous studies also indicate that the antihyperglycemic potential of curcumin in diabetic rats might be due to the regeneration of pancreatic $\beta$-cells, which were partially destroyed by alloxan thereby increasing insulin secretion. ${ }^{12}$ But the results obtained in the present study indicate that curcumin has no effect on insulin levels when taken in combination with gliclazide. However, curcumin is also known for its extra pancreatic-related antihyperglycemic effect in diabetic rats by decreasing hepatic glucose level, attenuation of free fatty acids, and TNF- $\alpha$ level as reported earlier. ${ }^{32}$

In the present study, the disposition of gliclazide after single oral dose was examined in rabbits with and without prior exposure to curcumin. Mean $\mathrm{C}_{\max }$ value of gliclazide obtained at 3-hour time interval can be correlated with peak glucose reduction and maximum insulin level linking the consistency of pharmacokinetic data with pharmacodynamic results in rabbits. This consistency is not altered by curcumin either in single- or multiple-dose treatments. One compartment open model was used to evaluate the pharmacokinetic parameters. The serum gliclazide levels obtained in the study were comparable to previous studies in rabbits with similar dose. ${ }^{3,18}$ Curcumin is reported in vitro to have the ability to induce drug-metabolizing enzyme CYP3A4 in liver microsomes and p-glycoprotein in intestinal cells. ${ }^{33}$ Similar results are obtained in vivo, where drugs such as celiprolol (p-glycoprotein substrate), midazolam, ${ }^{34}$ and norfloxacin ${ }^{35}$ (CYP3A4 substrate) when given in combination with curcumin resulted in increased $\mathrm{C}_{\max }$ and area under the curve of these drugs as they share a common substrate. Curcumin, CYP3A4 substrate, may not have any significant effect on the metabolism of gliclazide, which is primarily metabolized by CYP2C9 and partly by CYP3A4. This could probably explain the results obtained in this study where the pharmacokinetics 
of gliclazide was not altered by curcumin in both single- and multiple-dose treatment studies.

\section{Conclusion}

Current work attempts to shed light on the practices of polypharmacy where combination of curcumin and gliclazide is used. The study confirms that the interaction of curcumin with gliclazide is pharmacodynamic in nature as the glucose levels in animal models are significantly altered and no change in pharmacokinetics of gliclazide is observed. Since the interaction is observed in two dissimilar species, it is also likely to occur in humans. Hence, this combination needs monitoring of glucose levels periodically when administered for their clinical benefits in obese patients. However, further studies are necessary to determine the possibility of these interactions in clinic and also to determine the exact mechanism of action of such interactions.

\section{Acknowledgments}

The authors are thankful to Dr Reddy's Labs Ltd, Hyderabad, India, for providing gift sample of gliclazide for the research work. The authors are grateful to the management of Delve labs Ltd, Hyderabad, India, for providing support in supplying and conducting of animal experiments. The authors are also thankful to Renuka Pillai, Aurigene Discovery Technologies Limited, Hyderabad, India, for reviewing and providing insights for the manuscript.

\section{Author contributions}

KEK designed the research and interpreted the data; VLK designed the research, performed, analyzed, and drafted the manuscript. Both authors contributed toward data analysis, drafting and revising the paper and agree to be accountable for all aspects of the work.

\section{Disclosure}

The authors report no conflicts of interest in this work.

\section{References}

1. Chien CF, Wu YT, Lee WC, Lin LC, Tsail TH. Herb-drug interaction of Andrographis paniculata extract and andrographolide on the pharmacokinetics of theophylline in rats. Chem Biol Interact. 2010;184(3): 458-465.

2. Feinleib M. Epidemiology of obesity in relation to health hazard. Ann Intern Med. 1985:103(Pt 2):1019-1024.

3. Satyanarayana S, Kilari EK. Influence of nicorandil on the pharmacodynamics and pharmacokinetics of gliclazide in rats and rabbits. Mol Cell Biochem. 2006;291(1-2):101-105.

4. Brien RC, Luo M, Balaza N. In vitro and in vivo antioxidant properties of gliclazide. J Diabetes Complications. 2000;14(4):201-206.

5. Shishir S, Gautam S, Bharat BA. Curcumin: getting back to the roots. Ann NY Acad Sci. 2005;1056:206-217.
6. Chuengsamarn S, Rattanamongkolgul S, Luechapudiporn R, Phisalaphong C, Jirawatnotai S. Curcumin extract for prevention of type 2 diabetes. Diabetes Care. 2012;35(11):2121-2127.

7. Aggarwal BB. Targeting inflammation-induced obesity and metabolic diseases by curcumin and other nutraceuticals. Annu Rev Nutr. 2010;30:173-199.

8. Ramirez-Tortosa MC, Aguilera CM, Quiles JL, Gil A. Influence of dietary lipids on lipoprotein composition and $\mathrm{LDL} \mathrm{Cu}^{(2+)}$-induced oxidation in rabbits with experimental atherosclerosis. Biofactors. 1998;8(1-2):79-85.

9. Jang EM, Choi MS, Jung UJ, et al. Beneficial effects of curcumin on hyperlipidemia and insulin resistance in high-fat-fed hamsters. Metabolism. 2008;57(11):1576-1583.

10. Ejaz A, Wu D, Kwan P, Meydani M. Curcumin inhibits adipogenesis in 3T3-L1 adipocytes and angiogenesis and obesity in C57/BL mice. $J$ Nutr. 2009;139(5):919-925.

11. El-Moselhy M, Taye A, Sharkawi SS, El-Sisi SF, Ahmed AF. The antihyperglycemic effect of curcumin in high fat diet fed rats. Role of TNF- $\alpha$ and free fatty acids. Food Chem Toxicol. 2011;49(5):1129-1140.

12. El-Azab M, Attia F, El-Mowafy A. Novel role of curcumin combined with bone marrow transplantation in reversing experimental diabetes: effects on pancreatic islet regeneration, oxidative stress, and inflammatory cytokines. Eur J Pharmacol. 2011;658(1):41-48.

13. Thapliyal R, Maru GB. Inhibition of cytochrome P450 isoenzymes by curcumins in vitro and in vivo. Food Chem Toxicol. 2001;39(6):541-547.

14. Zhang W, Lim LY. Effects of spice constituents on P-glycoproteinmediated transport and CYP3A4-mediated metabolism in vitro. Drug Metab Dispos. 2008;36(7):1283-1290.

15. Shaw SR, Nihal M, Ahmad N. Dose translation from animal to human studies revisited. FASAB J. 2007;22(3):659-661.

16. Mastan SK, Eswar Kumar K. Influence of non-nucleoside reverse transcriptase inhibitors (efavirenz and nevirapine) on the pharmacodynamic activity of gliclazide in animal models. Diabetol Metab Syndr. 2009;1(1):15.

17. Mastan SK, Kumar KE. Effect of antiretroviral drugs on the pharmacodynamics of gliclazide with respect to glucose-insulin homeostasis in animal models. $J$ Exp Pharmacol. 2010;2:1-11.

18. Eswar Kumar K, Mastan SK. Influence of efavirenz and nevirapine on the pharmacodynamics and pharmacokinetics of gliclazide in rabbits. $J$ Endocrinol Metab. 2011;1(3):113-124.

19. Heikkila RE. The prevention of alloxan-induced diabetes in mice by dimethyl sulfoxide. Eur J Pharmacol. 1977;44(2):191-193.

20. Riley V. Adaptation of orbital bleeding technique to rapid serial blood studies. Proc Soc Exp Biol Med. 1960;104:751-754.

21. Matthews DR, Hosker JP, Rudenski AS, Naylor BA, Treacher DF, Turner RC. Homeostasis model assessment: insulin resistance and $\beta$-cell function from fasting plasma glucose and insulin concentrations in man. Diabetologia. 1985;28(7):412-419.

22. Bonora E, Targher G, Alberiche M, et al. Homeostasis model assessment closely mirrors the glucode clamp technique in the assessment of insulin sensitivity: studies in subject with various degrees of glucose tolerance and insulin sensitivity. Diabetes Care. 2000;23(1):57-63.

23. Gupta RC, Atul BV. Drug metabolism studies in animal models. Ind $J$ Pharmacol. 2000;32(4):S62-S66.

24. Mastan SK, Eswar Kumar K. Effect of ritonavir on the pharmacodynamics of gliclazide in animal models. Diabetologia Croatica. 2009;38(4):105-113.

25. Satyanarayana S, Kumar KE, Rajashekar J, Thomas L, Rajanna S, Rajanna B. Influence of aqueous extract of fenugreek-seed powder on the pharmacodynamics and pharmacokinetics of gliclazide in rats and rabbits. Therapy. 2007;4:457-463.

26. Davis TME, Daly F, Walsh JP, Ilett KF, Beilby JP, Dusci LJ, Barrett PHR. Pharmacokinetics and pharmacodynamics of gliclazide in Caucasians and Australian Aborigines with type 2 diabetes. Br J Clin Pharmacol. 2000;49(3):223-230.

27. Ma A, Kamp M, Bird B. The effects of long term gliclazide administration on insulin secretion and insulin sensitivity. Aus $N Z J$ Med. 1989;19(1):14-49. 
28. Vanhaeften TW, Vaneman TF, Gerich JE. Influence of gliclazide on glucose stimulated insulin release in man. Metabolism. 1991;40(7): 751-755.

29. Wang Z, Sun W, Huang CK, et al. Inhibitory effects of curcumin on activity of cytochrome P450 2C9 enzyme in human and 2C11 in rat liver microsomes. Drug Dev Ind Pharm. 2015;41(4):613-616.

30. Nabavi SF, Thiagarajan R, Rastrelli L, Daglia M, Sobarzo-Sánchez E, Alinezhad H, Nabavi SM. Curcumin: a natural product for diabetes and its complications. Curr Top Med Chem. 2015;15(23):2445-2455.

31. Ali Hussain HE. Hypoglycemic, hypolipidemic and antioxidant properties of combination of curcumin from Curcuma longa and partially purified product from Abroma augusta, Linn. in Streptozotocin induced diabetes. Indian J Clin Biochem. 2002;17(2):33-43.
32. Zeinab G, Azita H, Parvin M. Anti-hyperglycemic and insulin sensitizer effects of turmeric and its principle constituent curcumin. Int $J$ Endocrinol Metab. 2014;12(4):e18081.

33. Hsieh YW, Hang CY, Yang SY, Peng YH, Yu CP, Chao PD, Hou YC. Oral intake of curcumin markedly activated CYP3A4: in vivo and ex vivo studies. Sci Rep. 2014;4:6587.

34. Zhang W, Tan TM, Lim LY. Impact of curcumin-induced changes in P-glycoprotein and CYP3A expression on the pharmacokinetics of peroral ceriprolol and midazolam in rats. Drug Metab Dispos. 2007;35(1): $110-115$.

35. Pavitra BH, Prakesh N, Jaykumar K. Modification of pharmacokineyics of norfloxacin following oral administration of curcumin in rabbits. JVet Sci. 2009;10(4):293-297.
Journal of Experimental Pharmacology

\section{Publish your work in this journal}

The Journal of Experimental Pharmacology is an international, peerreviewed, open access journal publishing original research, reports, reviews and commentaries on all areas of laboratory and experimental pharmacology. The manuscript management system is completely online and includes a very quick and fair peer-review system.

\section{Dovepress}

Visit http://www.dovepress.com/testimonials.php to read real quotes from published authors. 